\title{
Effect of vacuum oxy-nitrocarburizing on the microstructure of tool steels: an experimental and modeling study
}

\author{
Maria Nikolova ${ }^{1, *}$, Danail Nikolov ${ }^{1}$, Bora Derin $^{2}$, and Emil Yankov ${ }^{1}$ \\ ${ }^{1}$ University of Ruse “Angel Kanchev”, Dept. of Material science and Technology, 8 Studentska Str., \\ Ruse, Bulgaria \\ ${ }^{2}$ Istanbul Technical University, Metallurgical and Materials Eng. Dept., Maslak, Istanbul, Turkey
}

\begin{abstract}
The thermochemical treatments of tool steels improve the performance of the components with respect to surface hardness, wear and tribological performance as well as corrosion resistance. Compared to the conventional gas ferritic nitrocarburizing process, the original vacuum oxy-nitrocarburizing is a time-, cost-effective and environmentally-friendly gas process. Because of the oxidizing nature of the gas atmosphere, there is no need to perform subsequent post-oxidation.In this study, a vacuum oxynitrocarburizing process was carried out onto four tool steels (AISI H10, $\mathrm{H} 11, \mathrm{H} 21$ and D2) at $570{ }^{\circ} \mathrm{C}$, after hardening and single tempering. The structural analysis of the compound and diffusion layers was performed by optical and electron microscopy, X-ray diffraction and glow discharge optical emission spectrometry (GDOES) methods. A largely monophase $\varepsilon$ layer is formed with a carbon accumulation at the substrate adjacent area. The overlaying oxides adjacent to the $\varepsilon$-carbonitride phase contained $\mathrm{Fe}_{3} \mathrm{O}_{4}$ (magnetite) as a main constituent. A thermodynamic modelling approach was also performed to understand and optimize the process. The "Equilib module" of FactSage software which uses Gibbs energy minimization method, was used to estimate the possible products during vacuum oxynitrocarburising process.
\end{abstract}

\section{Introduction}

One of the cheapest and effective ways to improve the properties of the tool steels is to modify their surfaces through thermo-chemical treatments. Below the eutectoid temperature nitriding and nitrocarburizing that prevent dimensional distortions are usually applied. Because of the existence of oxidizing species $\left(\mathrm{H}_{2} \mathrm{O}\right.$ and $\left.\mathrm{CO}_{2}\right)$ in the gas nitrocarburizing atmosphere, the process held at sub-critical temperature for Fe-N system in ammonia $\left(\mathrm{NH}_{3}\right)$ and carbon dioxide $\left(\mathrm{CO}_{2}\right)$ is called oxy-nitrocarburizing $(\mathrm{ONC})$ [1].

The results from the thermo-chemical treatment vary considerably depending on the substrate material chosen, gas atmosphere and treatment conditions [2, 3]. During the nitrocarburizing process hard compound and supporting diffusion layers underneath are

Corresponding author: mpnikolova@,uni-ruse.bg 
formed. The first one improves the corrosion resistance [4] and tribological (erosion wear and galling) properties of the die [5,6] but when this "white" layer becomes highly porous and thick, it turns brittle. During nitrocarburizing of tool steels the compound layer with hard $\varepsilon$-carbonitride approaches $100 \%$ of the total volume with a certain degree of porosity [7] and oxides over it depending on the gas atmosphere used. The presence of oxygen plays important role in the process because it acts like a catalyst for $\varepsilon$-phase formation [8]. It is also known that the formation of some $\mathrm{Fe}_{3} \mathrm{O}_{4}$ in the surface layers improves the wear [9, $10]$ and corrosion resistance [11].

The underlying diffusion layer is responsible for the strengthening that enhances wear resistance and fatigue endurance [12-14] since the nitride/carbonitride phases in it are disperse and coherently bounded. In the presence of nitride stabilizing elements reactive diffusion of nitrogen with alloy carbides takes place.

Although the structure and the properties of gas nitrocarburizing steels have been subject of intense studies for a large number of years, the actual understanding of the influence of particular factors is still missing. It is not clear from the literature to what extent the external pressure and its variation during the gas nitrocarburizing could influence the structure, thickness and properties of the compound and diffusion layers. Additionally, as the gas nitrocarburizing technology of tool steels generally features long treatment, higher gas and energy consumption, thick and brittle compound layer and low environmental efficiency, the conventional gas process provides some restrictions.

In order to overcome the above mentioned weaknesses, the innovative and original gas ONC technology at low pressure is held at short cycle times that are employed to prevent surface embrittlement. The change in the gas pressure enables control on the formation of consistent surface layers with desirable thickness and properties. This is because the low pressure conditions during the first stage of the process thermodynamically destabilize the iron-nitride formation that postpones the compound layer growth [15].In contrast, a short incubation time for compound layer formation during the conventional nitrocarburizing process is needed [16]. The dense structure of this "white" layer acts like a diffusion barrier that hinders the saturation of the diffusion layer in depth and the former becomes thick and porous. During the vacuum ONC of tool steels the alloying elements nitride formation is not influenced by the change in pressure and a large microstructural and morphological modification of the surface layers could be expected.

The vacuum $\mathrm{ONC}$ is employed in a cycle gas flow regime at pressure values varying between $1.10^{4} \mathrm{~Pa}$ and $8.10^{4} \mathrm{~Pa}$ as the former is reach when pumping down the inert or exhausted gases and the second - when dissociation slowly occurs and gas reactions take place. Therefore, another advantage of the vacuum ONC process is the cycling gas flow that allows a longer stay of the reactive molecules in the chamber and their stronger tendency to decompose and interact. Moreover, the periodic pumping down the gas phase from the vacuum chamber clears the chemisorbed gas products from the surface at regular intervals. This also enables the full utilization of the reactive gases. In this way the gas consumption is significantly low and the process is cost effective, safety and environmentally-friendly. Simultaneously, the thermodynamics of the phase transformations allows certain control by the non-conventional external conditions.

The mechanical strength of both layers depends on the volume fraction and the types of the crystal lattice of the resultant products after ONC. As mentioned above the ONC process possesses attractive advantages and perspectives but its capabilities in terms of tool steel surface enhancement remains unexamined. On the other hand, the microstructure evolution prediction and control during the thermo-chemical process are thus very important. The ongoing efforts to simulate the nitriding and nitrocarburizing processes has been continuing for over 20 years because when calculations applied provide quick and reliable results, they could be very important in industrial applications. Unfortunately, there 
is still a lack of coincidence of the modelling the microstructure and composition evolution and the experimental results during nitrocarburizing.

The thermodynamic databases of "Equilib module" of FactSage software could be used when constructed to simulate the thermodynamic behaviour and phase transformation of the multicomponent systems depending on the composition, temperature and pressure. In order to validate the relevance of the thermodynamic calculations, the composition dependent transformations under the influence of $\mathrm{N}, \mathrm{C}$ and/or $\mathrm{O}$ need to be experimentally determined. For this purpose, four different tool steels (one with less high temperature strength and three for hot work) are examined for the influence of the additional elements on the composition and structure of both compound and diffusion layers. These steels presents a wide variation in composition but they have some common elements such as $\mathrm{C}, \mathrm{Fe}, \mathrm{Cr}, \mathrm{V}$ and Mo. Moreover, the four grades are commonly use nitriding/nitrocarburizing steels for extrusion dies in extruding aluminium or plastics that maintains high impact strength in quenched and tempered condition. The experimental data of the microstructure, chemical and phase composition of the ONC tool steels are presented and the applicability of the thermodynamic modelling approach is verified.

\section{Experimental procedures}

\subsection{Materials, heat treatment, samples preparation}

Four different steel grades - AISI H10 (DIN 1.2365 EN 32CrMoV12-28, 3X3M3Ф), AISI H11 (DIN 1.2343, EN X37CrMoV5-1, 4X5MФC), AISI H21 (DIN 1.2581, EN X30WCrV9-3, 3X2B8Ф) and AISI D2 (DIN 1.2379, EN X153CrMoV12, H12MF) with composition shown in Table 1 (measured by quantometer SpectroMaxx) were subject to the vacuum ONC process. All the experiments were carried out with round or quadrangular specimens with sizes of about $25 \mathrm{~mm}$ and a thickness of $10 \mathrm{~mm}$. The samples were used in quenched in agitated mineral oil and tempered condition, which was obtained by conventional heat treatment. The heat treatment regimens were shown in Table 2. The second time tempering was physically coupled with the thermochemical treatment. The microstructure of the tool steel samples prior to the thermochemical treatment was tempered martensite with carbides.

Table 1.Chemical composition of the steel samples (wt.\%) before the thermochemical treatment.

\begin{tabular}{|c|c|c|c|c|c|c|c|c|c|c|}
\hline $\begin{array}{c}\text { Element, } \\
\text { wt.\% }\end{array}$ & $\mathbf{C}$ & Si & Mn & Cr & Mo & V & W & P & S & Fe \\
\hline AISI H10 & 0.332 & 0.52 & 0.409 & 3.57 & 3.73 & 0.70 & 0.114 & 0.023 & 0.0099 & Bal \\
\hline AISI H11 & 0.36 & 1.18 & 0.423 & 5.38 & 1.32 & 0.33 & 0.034 & 0.034 & 0.0051 & Bal \\
\hline AISI H21 & 0.292 & 0.436 & 0.373 & 2.57 & 0.053 & 0.212 & 8.38 & 0.022 & 0.013 & Bal \\
\hline AISI D2 & 1.51 & 0.275 & 0.386 & 13.14 & 0.61 & 0.203 & 0.04 & 0.021 & 0.0075 & Bal \\
\hline
\end{tabular}

Table 2. Preliminary heat treatment of the samples.

\begin{tabular}{|c|c|c|c|c|}
\hline Steel/Heat treatment & AISI H10 & AISI H10 & AISI H21 & AISI D2 \\
\hline Quenching & $1000-1020$ & $1040-1050$ & $1130-1140$ & $1040-1050$ \\
temperature, ${ }^{\circ} \mathrm{Ctime}$ & $10 \mathrm{~min}$ & $10 \mathrm{~min}$ & $10 \mathrm{~min}$ & $10 \mathrm{~min}$ \\
\hline Tempering temperature, ${ }^{\circ} \mathrm{C}$ & $540-550$ & $540-550$ & $540-550$ & $540-550$ \\
hour & 1 hour & 1 hour & 1 hour & 1 hour \\
\hline
\end{tabular}




\subsection{Thermo-chemical treatment}

A hole of $2 \mathrm{~mm}$ in diameter was drilled near the edge of the samples for holding them during the process. The decarburized layer that formed at the surface during the heat treatment was removed by grinding. Before the thermochemical process, the steel samples were mirror polished, lapped and degreased. The oxy-nitrocarburized layers were prepared by a vacuum process carried out in industrial equipment for 7 hours at $570^{\circ} \mathrm{C}$ in $\mathrm{NH}_{3}$ and $\mathrm{CO}_{2}$ atmosphere (ratio 90:10 vol. \%, respectively) in a cycling gas flow rate. During stage I of the process the pressure in the vacuum chamber was $7-8.10^{4} \mathrm{~Pa}$ for the first five hours and increased up to $1.10^{5} \mathrm{~Pa}$ during the last 2 hours (stage II) [17]. The cooling off was carried out in the $\mathrm{NH}_{3}$ atmosphere till $400^{\circ} \mathrm{C}$ and after that in $\mathrm{N}_{2}$ in air.

\subsection{Characterization}

Cross sections of the oxy-nitrocarburized samples were prepared by conventional metallographic techniques. The light optical microscopy (LOM) was performed on cross sections of the samples using a Neophot 21 (Zeiss, Jena) microscope after etching the samples with picral reagent. An oil immersion objective for reflected light was applied. The average thickness of the compound and diffusion layers was determined in cross-section using a digital camera images.

The metallographically prepared sections were also used for scanning electron microscopy (SEM) analysis. The secondary electron micrograph of the surface of the ONC samples are taken by JEOL JSM-5510 (Japan) and accelerating beam voltage of $10 \mathrm{kV}$, vacuum pressure below $1,33.10^{-5}$ mbar. Prior the analysis each sample was coated with thin layer of gold to reduce electric charge of the specimens scanned and to increase the image resolution.

For the phase analysis X-ray diffraction (XRD) was performed on the top surface of the samples using URD-6 diffractometer with Fe-K $\alpha$ line-focused radiation applying BraggBrentano geometry. The diffractograms were analysed over a $2 \theta$ range of $30^{\circ}$ to $120^{\circ}$ degree with a step size of $0.1^{\circ} 2 \theta$ and continuing time of $1.5 \mathrm{sec} / \mathrm{step}$. The Fe-Ka radiation source was used at $30 \mathrm{kV}$ and $20 \mathrm{~mA}$. XRD Match!3 software was used to determine the phases of the resulting data.

The main metalloid elements participating in the $\mathrm{ONC}$ process $-\mathrm{N}, \mathrm{C}$ and $\mathrm{O}$ composition-depth profiles were determined by glow discharge optical emission spectroscopy (GDOES) of LECO GDS-850A.

\section{Results and discussion}

\subsection{Modelling}

Before the $\mathrm{ONC}$ experiments, $\mathrm{Fe}-\mathrm{N}$ and $\mathrm{Fe}-\mathrm{N}-\mathrm{C}$ phase diagram calculations were performed by using advanced "phase diagram" module of FactSage 7.0 [18]. In the calculations, SGTE2014 database was selected to detect the liquid and solid solutions in the system.

Iron-nitrogen interaction is important to understand the nitriding process phenomena. Figure 1 illustrates a Fe-N binary phase diagram calculated by FactSage at 1 bar. As expected, nitrogen is less soluble in the ferritic $\alpha$-Fe phase (BCC_A2) rather than austenitic $\gamma$-Fe phase (FCC_A1). Below eutectoid temperature $\left(\sim 587^{\circ} \mathrm{C}\right)$, iron nitride $\gamma^{\prime}$ phase $\left(\mathrm{M}_{4} \mathrm{~N}\right)$ occurs when the nitrogen level exceeds solubility limit of $\alpha$-Fe. Subsequent $\mathrm{Fe}_{2} \mathrm{~N}_{1-x}$ phase, which is so called $\varepsilon$ phase (HCP_A3), emerges after $\mathrm{N} /(\mathrm{Fe}+\mathrm{N})$ mole ratio exceeds 0.2 . 


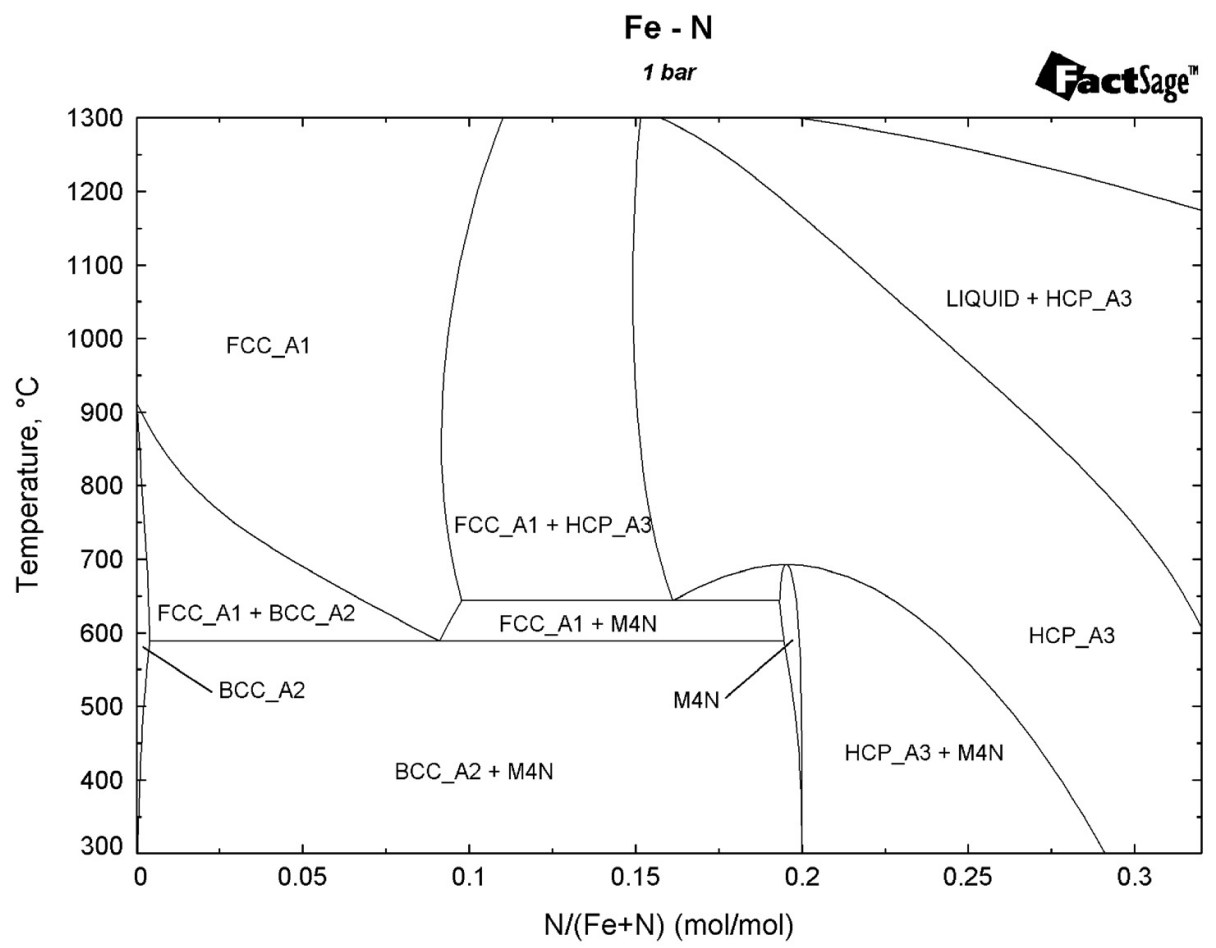

Fig. 1. Fe-N binary phase diagram calculated by FactSage at $1.10^{5} \mathrm{~Pa}(1 \mathrm{bar})$.

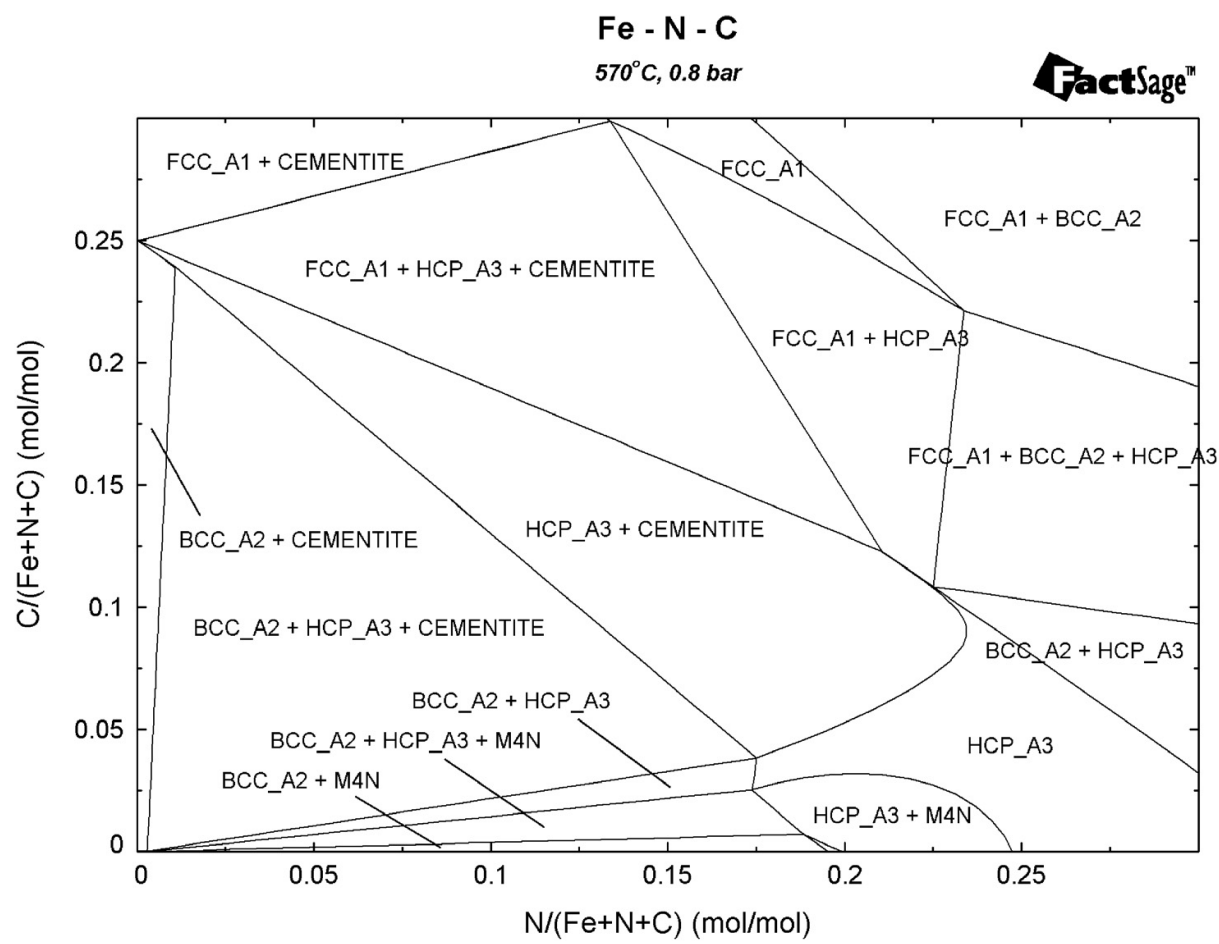

Fig. 2. Fe-N-C ternary phase diagram calculated by FactSage at $570{ }^{\circ} \mathrm{C}$ and $8.10^{4} \mathrm{~Pa}(0.8$ bar). 
In order to simulate the ONC process in equilibrium condition, an $\mathrm{Fe}-\mathrm{N}-\mathrm{C}$ ternary phase diagram was calculated by FactSage at $570{ }^{\circ} \mathrm{C}$ and $8.10^{4} \mathrm{~Pa}$. Figure 2 shows that, very high concentrations of $\mathrm{N}$ and low concentrations of carbon in the iron, which may represent the top layer of the transformed area, stimulate the formations of mixture of $\gamma^{\prime}\left(\mathrm{M}_{4} \mathrm{~N}\right)$ and $\varepsilon$ (HCP_A3) phases or only single $\varepsilon$ (HCP_A3) phase in the system. When carbon concentration is increased at these levels, cementite or $\alpha$-Fe phases (BCC_A2) are formed, respectively, together with $\varepsilon\left(\mathrm{HCP}_{-} \mathrm{A} 3\right)$ phase.

\subsection{Experimental verification}

The microstructure of AISI H11 (Fig. 3b) steel is very similar to that of the ONC AISI H10 (Fig. 3a) steel, but the compound layer of the former appears to be thinner and the carbides in the diffusion layer looks slightly coarser. The quantity of the alloying elements in the solid solution (tempered martensite) is pre-determined by the initial heat treatment of the steel. Beneath the compound layer, the microstructure of the diffusion one that contains coarse laths of the tempered martensite outlined by the grains of the former austenite, is clearly seen. The lighter tempered martensite is represented by the darker looking C-rich regions (Fig. 3a and b). The carbon atoms released within the carbide-nitride transformation are expected to diffuse within the grain boundaries, where $\mathrm{Fe}_{3} \mathrm{C}$ is formed (Fig. $3 \mathrm{a}$ and $\mathrm{b}$ ).

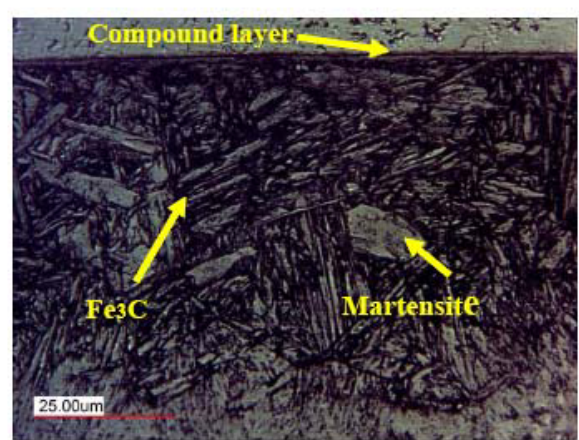

a)

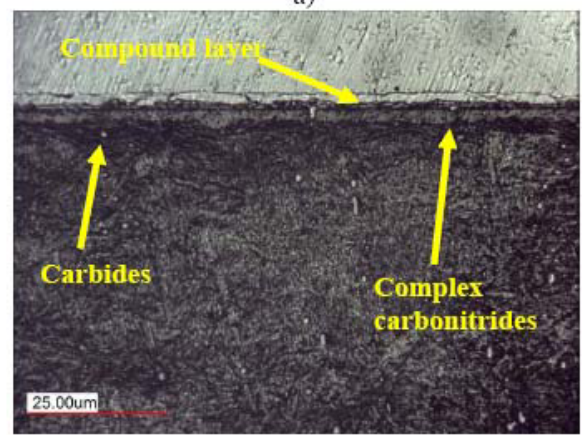

c)

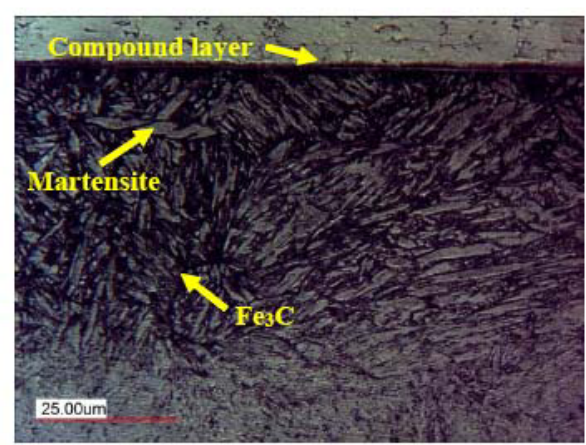

b)

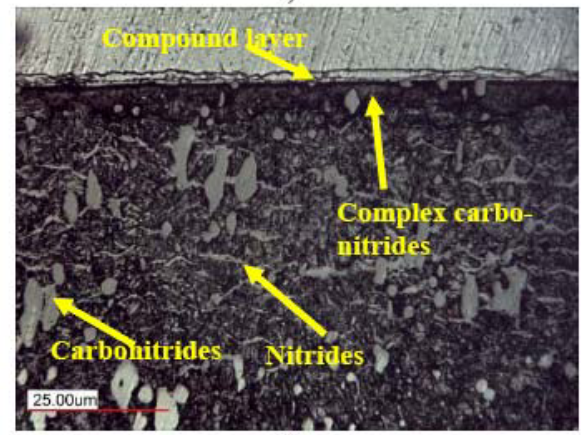

d)

Fig.3.Optical micrograph of cross-section of: a) ONC H11 steel; b) ONC H10 steel; c) ONC H21 steel; d) ONC H10 steel. All the samples are etched in picral.

In the ONC H21 steel (Fig. 3c) the interface between the compound and diffusion layers is well defined and seems dark and thick (beyond $5 \mu \mathrm{m}$ in depth). The tempered martensite structure of the diffusion layer seems more disperse than that of the previous samples. In 
this steel white-looking globular carbide phases are present in the diffusion zone. These are likely to be $\mathrm{W}$-containing carbides since although the $\mathrm{WN}$ formation may provide a higher structural stability, the small diffusivity of tungsten hinders this process. The compound layer of the ONC AISI D2 steel (Fig. 3d) appears to be somewhat thicker than that of the other samples. The former primary carbides in the diffusion layer that have become carbonitrides (with high carbon content), look darker than the phases with the same morphology located deeper in the diffusion layer. The bright nearly parallel with respect to the surface tubular phases are the Cr-containing nitirdes. Apparently, $\mathrm{Cr}$ in the ONC D2 alloy could be considered as mobile because of the conversion of the primary carbides $\left(\mathrm{M}_{23} \mathrm{C}_{6}\right)$ into carbonitrides/nitrides and the dissolution of carbides close to the compound layer interface. The "aging" of the nitrides in the diffusion layer is obvious because of the formation of large nitride crystallites.

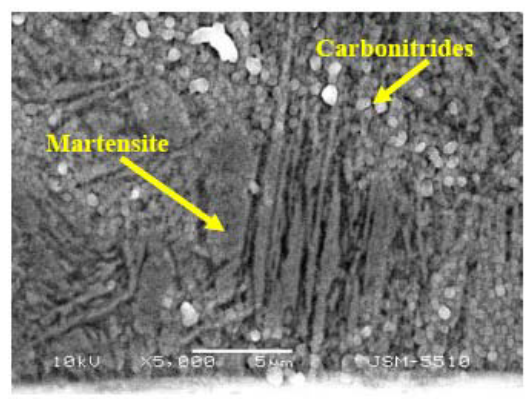

a)

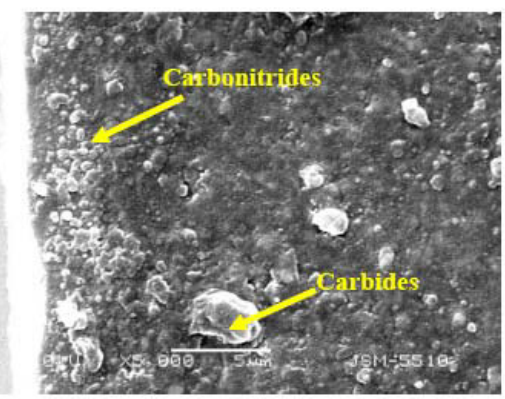

b)

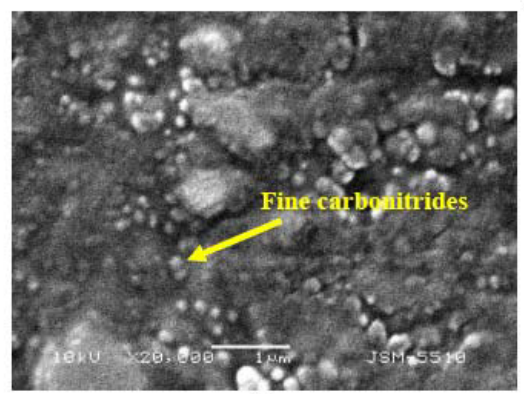

c)

Fig.4.Secondary electron micrographs of the ONC samples: a) structure of the diffusion layer of the ONC H10 steel - tempered martensite and carbonitreds; b, c) diffusion layer structure of the ONC H21 steel.

Since the carbon content in H10 steel is much lower than the equivalent to convert all the alloying elements in the $\mathrm{V}-, \mathrm{Cr}$ - and Mo-containing carbides, the martensite contains a substantial amount of dissolved alloying elements that are available for the development of disperse (carbo)nitrides that are shown on Fig. 4a. The white-looking spherical nitrides in the diffusion layer of the $\mathrm{H} 21$ sample (Fig. $4 \mathrm{~b}$ and c) have similar shape with the primary carbides, but there are far more disperse (Fig. 4c). It is reasonably to be considered that these are transformed $(\mathrm{Fe}-\mathrm{Cr})_{23} \mathrm{C}_{6}$ because the latter carbide nucleates faster during the tempering procedure phases when $\mathrm{W}$ is added [19]. During the prolonged ONC treatment and when the alloy element concentration is above $\sim 2$ wt.\% [20] the discontinuous precipitates coarsen into lamellae and spheres. 


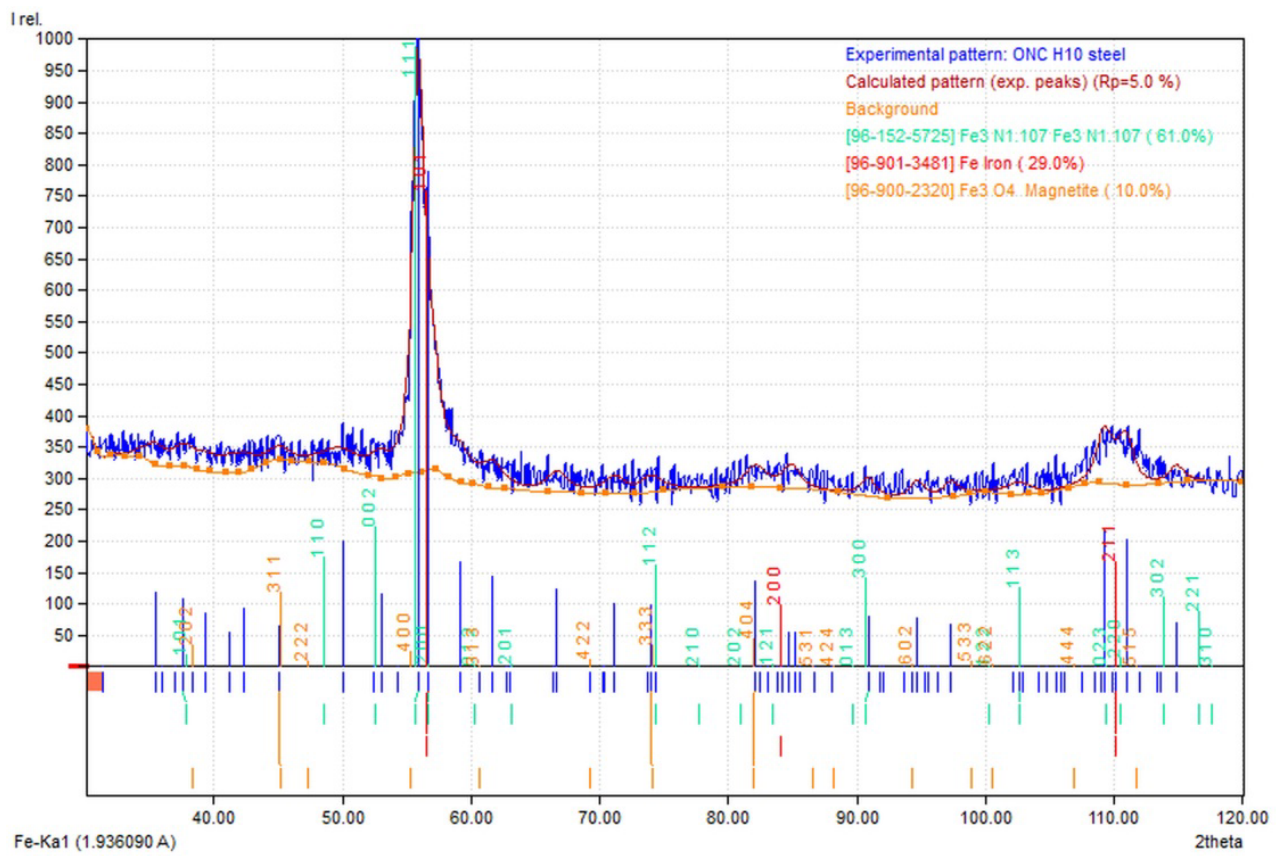

Fig.5. XRD diffractograms of the ONC AISI H10.

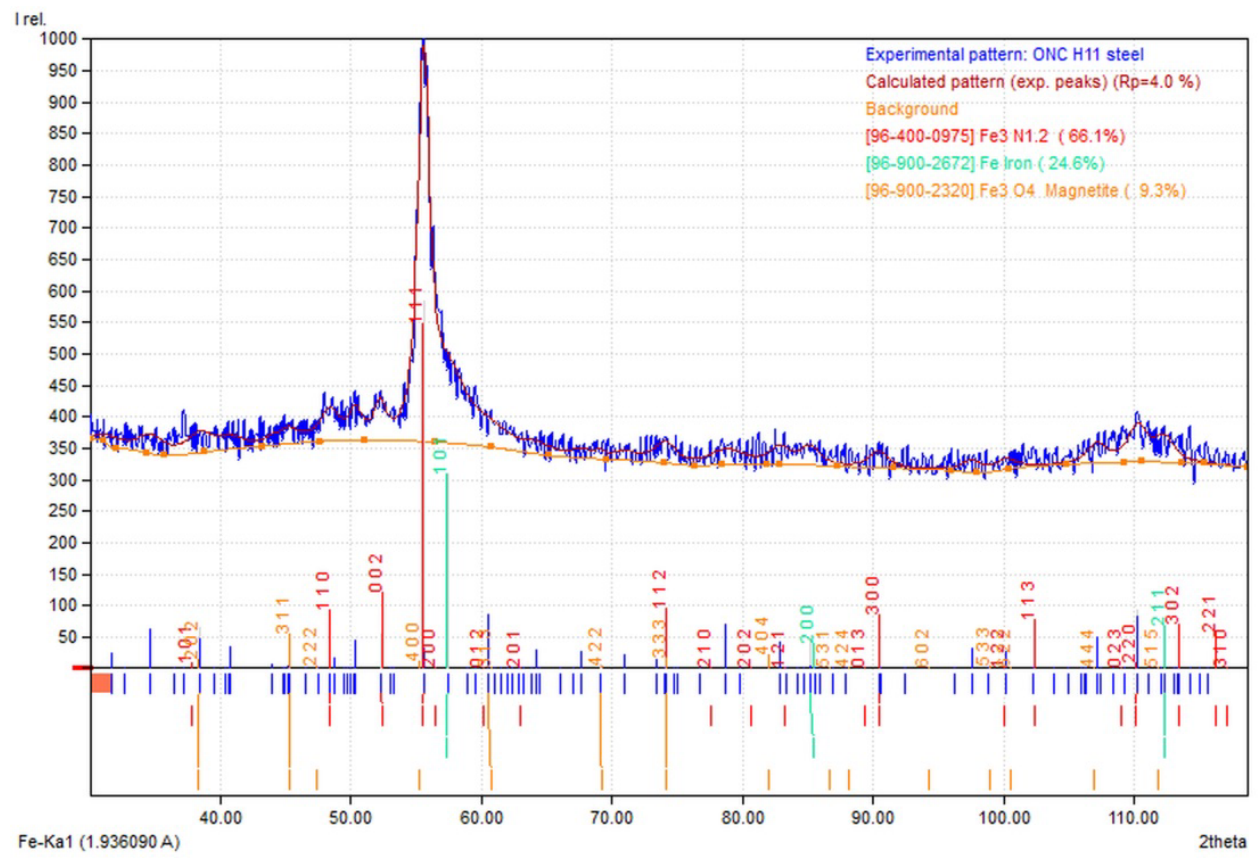

Fig.6. XRD diffractogram of the ONC AISI H11 steel.

The XRD analysis of the ONC AISI H10 steel reveals that $\varepsilon-\mathrm{Fe}_{2-3} \mathrm{~N}$ is the dominant phase together with minor peaks of ferrite $(\alpha-\mathrm{Fe})$ and magnetite $\left(\mathrm{Fe}_{3} \mathrm{O}_{4}\right)$. The diffraction lines of the $\varepsilon$-peak determines a phase stoichiometry close to $\mathrm{Fe}_{3} \mathrm{~N}_{1.107}$ (Fig. 5) with unit cell parameters $\mathrm{a}=4.7126 \AA \mathrm{c}=4.3752 \AA$. The unite cell parameter of the ferrite (tempered martensite) is determined to be near $\mathrm{a}=2.8920 \AA$. The surface $\varepsilon$-carbonitride is not 
oversaturated with nitrogen (slightly more than $12 \mathrm{wt} . \%$ ) and the compound layer is approximately $2 \mu \mathrm{m}$ thick (Fig. 9). At a distance of about $0.8 \mu \mathrm{m}$ the $\mathrm{N}$ and $\mathrm{C}$ concentration become merely equal (Fig. 10). The inside porosity of the $\varepsilon-\mathrm{Fe}_{2-3}(\mathrm{~N}-\mathrm{C})$ reaches a depth of about 0.5-0.8 $\mu \mathrm{m}$ judged from the oxygen concentration peak (Fig. 11), where $\mathrm{Fe}_{3} \mathrm{O}_{4}$ is formed (see XRD results).

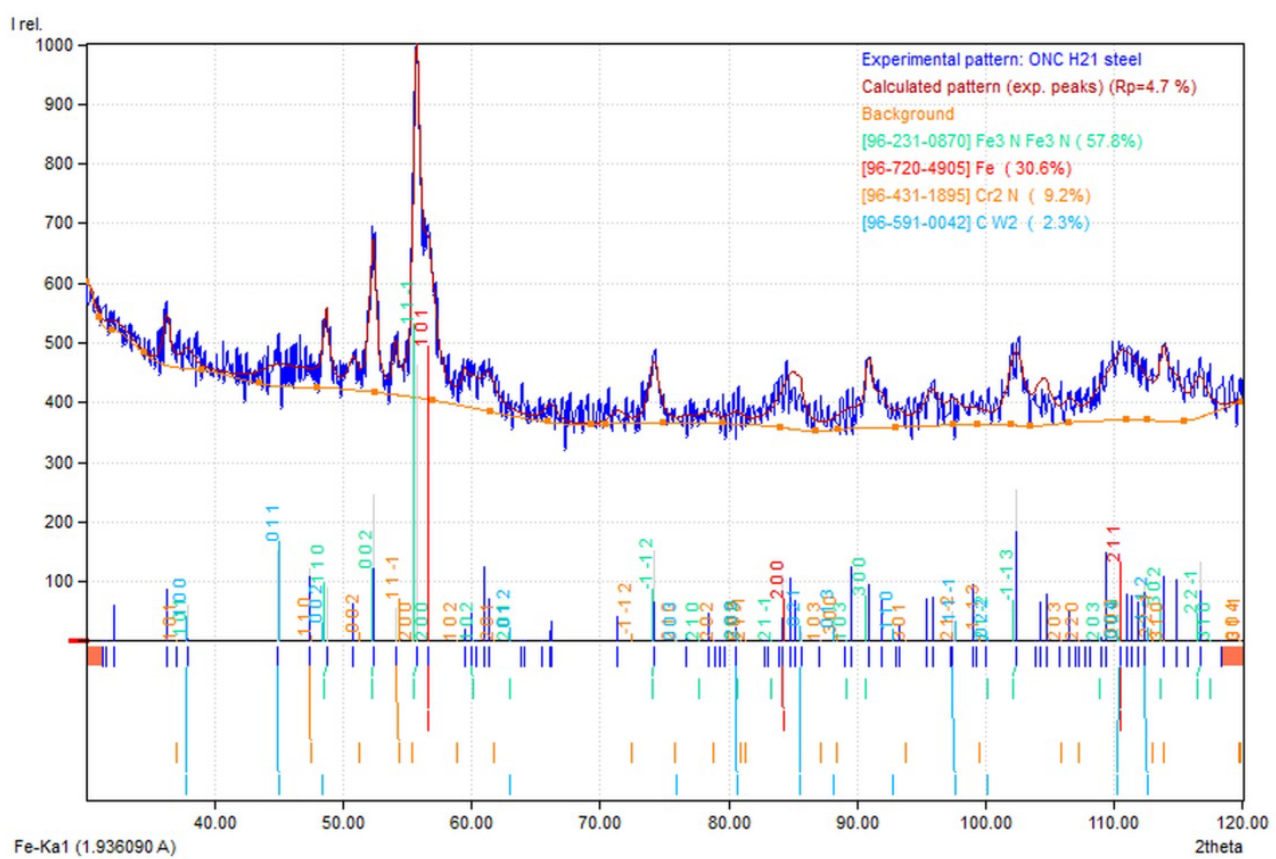

Fig. 7. XRD diffractogram of the ONC AISI H21 steel.

Taking account of the XRD results of the ONC H11 sample (Fig. 6), the composition of the compound layer constitutes monophase carbonitride with a stoichiometry close to $\mathrm{Fe}_{3} \mathrm{~N}_{1.2}$ and larger cell parameters $(\mathrm{a}=4.7241 \AA \mathrm{c}=4.3862 \AA)$ than the AISI H10 $\varepsilon$-phase. This indicates a higher interstitial atom content in the $\varepsilon$-phase. The tempered martensite cell parameter is smaller (approximately $\mathrm{a}=2.8550 \AA$ ). Within the $\varepsilon$-compound layer of the H11 steel, a significant decrease of the nitrogen concentration at a depth of $0.4-0.5 \mu \mathrm{m}$ has occurred and beyond it rises again up to 2 wt. \% (Fig. 9). This minimum in the nitrogen concentration underneath could be attributed to the diffusion of nitrogen to a larger depth evoked by nitride forming elements and the hindered nitrogen uptake and inward diffusion beyond $0.4 \mu \mathrm{m}$ depth where the carbon and oxygen concentration prevails (Fig. 10 and 11). 


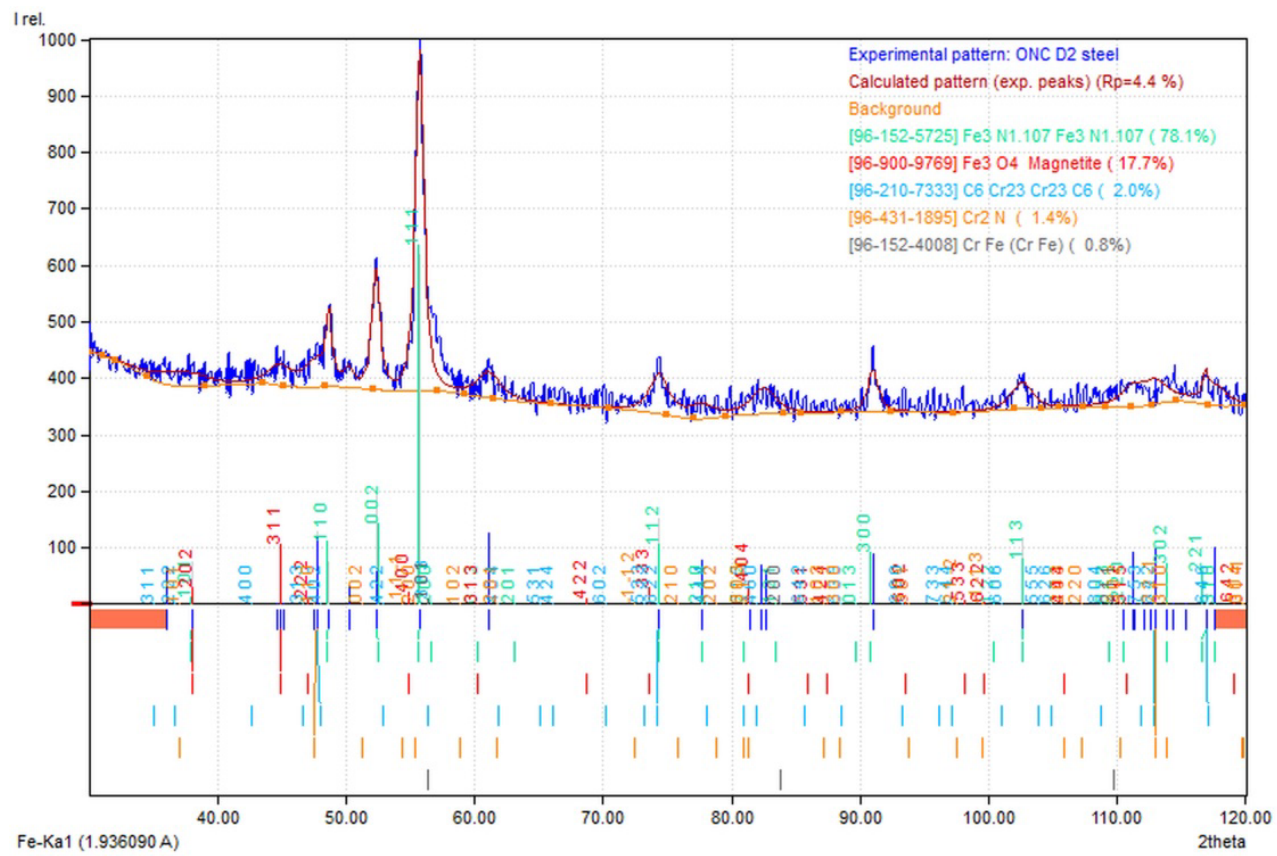

Fig.8. XRD diffractogram of the ONC AISI D2 steel.

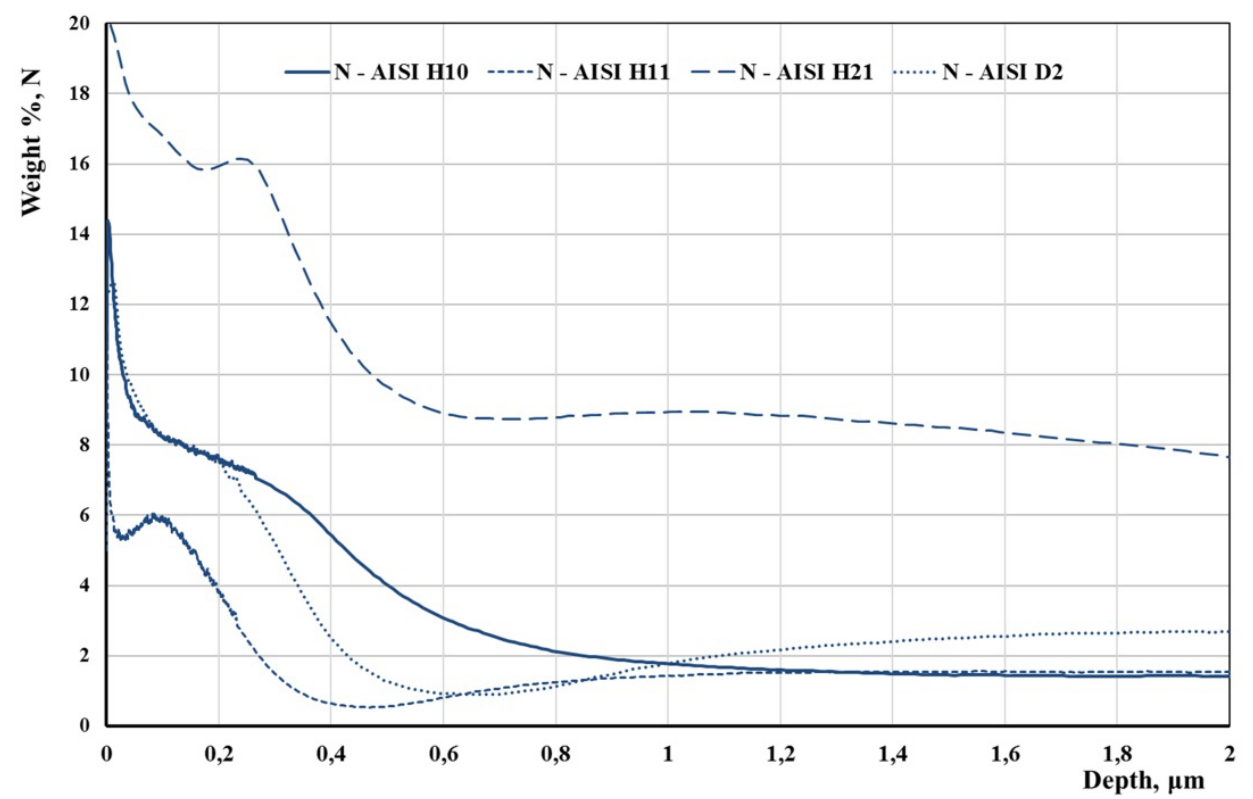

Fig. 9. GDOES concentration-depth profiles of nitrogen of the ONC samples.

The XRD spectra of the AISI H21 steel (Fig. 7) indicate that the main phases after ONC are the $\varepsilon$-carbonitride and magnetite. The $\varepsilon$-carbonitride formula corresponds to $\mathrm{Fe}_{3}$ Nwithunit cell parameters $\mathrm{a}=4.7160 \AA \mathrm{c}=4.3940 \AA$. In the compositionally complex surface region, magnetite is formed on the inside of the $\varepsilon$-carbinitride pores at level beneath $0.5 \mu \mathrm{m}$ equal to the depth of the porosity determined by the GDOES results (Fig. 11).In the XRD diffractogram of the ONC AISI H21steel(Fig. 7) minor peaks of the detected phases 
belong to $\mathrm{Cr}_{2} \mathrm{~N}$ with hexagonal lattice structure. Small percentage of $\mathrm{W}_{2} \mathrm{C}$ phase is also determined using XRD analysis. In the AISI H21 steel the registered $\mathrm{N}$ concentration at the surface is the highest of all samples and a smoother drop in the nitrogen concentration in depth is observed (Fig. 9). The carbon concentration does not exceed that of the nitrogen but forms two separate carbon hills (Fig. 10).

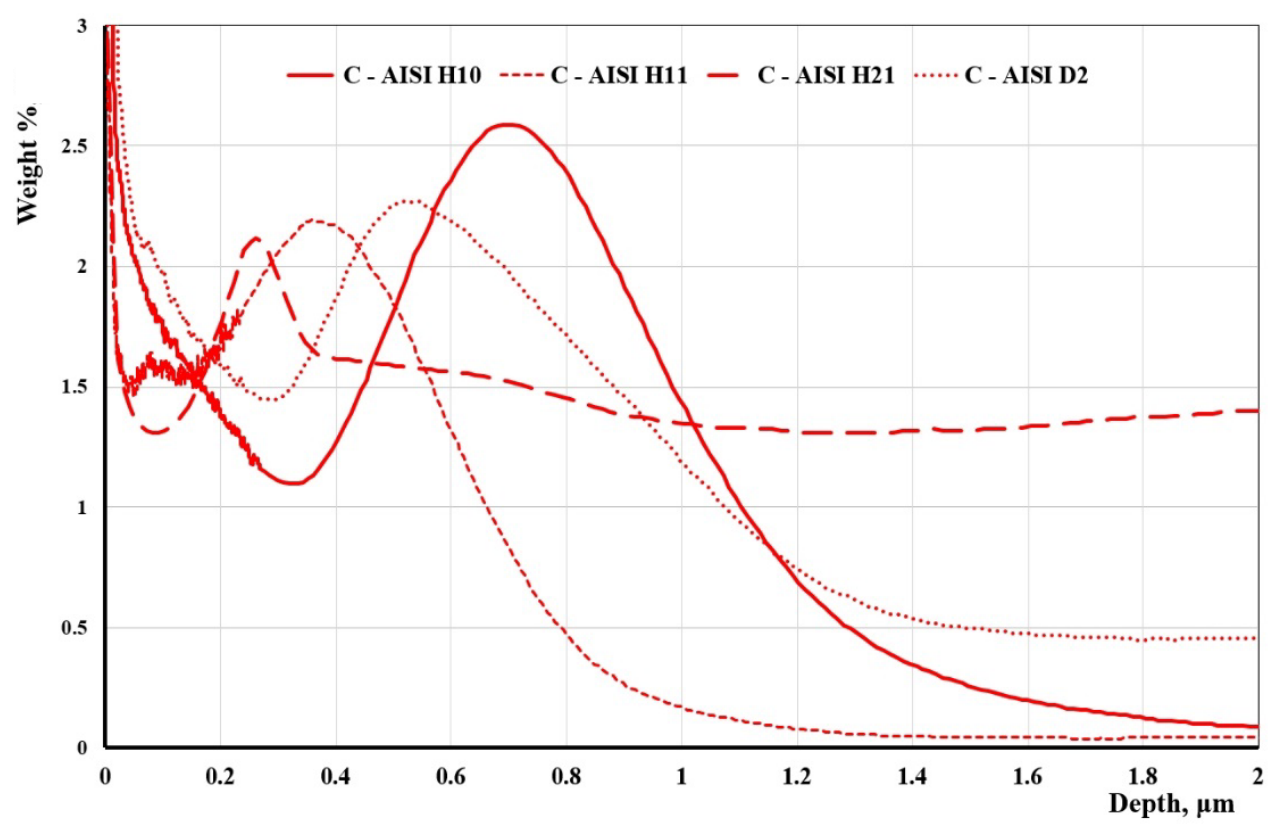

Fig. 10. GDOES concentration-depth profiles of carbon of the ONC samples.

The XRD analysis of the ONC D2 sample (Fig. 8) demonstrates intense peaks of $\varepsilon$ $\mathrm{Fe}_{3} \mathrm{~N}_{1.107}$ and $\mathrm{Fe}_{3} \mathrm{O}_{4}$ and minor peaks from $\mathrm{Cr}_{23} \mathrm{C}_{6}, \mathrm{Cr}_{2} \mathrm{~N}$ and $\mathrm{Cr}-\mathrm{Fe}$ ferrite. The $\varepsilon$-compound layer shows limited amount of porosity as a consequence of the $\mathrm{ONC}$ treatment. The thicker compound layer is evidenced by the presence of more than six $\varepsilon-\mathrm{Fe}_{2-3}(\mathrm{~N}, \mathrm{C})$ distinct reflections. Their positions correspond to $\varepsilon-\mathrm{Fe}_{3} \mathrm{~N}_{1.107}$ with lattice cell parameters $\mathrm{a}=4.7126$ $\AA \mathrm{c}=4.3752 \AA$. The detected reflections show the presence of hexagonal $\mathrm{Cr}_{2} \mathrm{~N}$ and cubic $\mathrm{Cr}_{23} \mathrm{C}_{6}$ phases. The Cr-containing tempered martensite $(\mathrm{Cr}-\mathrm{Fe})$ is found to have larger $(\mathrm{a}=$ $2.9000 \AA$ ) cubic unit cell relative to the others.

From the GDOES results of the ONC H21 and D2 steel (Fig. 9) is clear that the higher the content of the nitride forming elements, the larger the capacity of the diffusion layer for binding nitrogen in it. Therefore, the nitrogen concentration in the diffusion layer is relevant to the alloying elements concentration. 


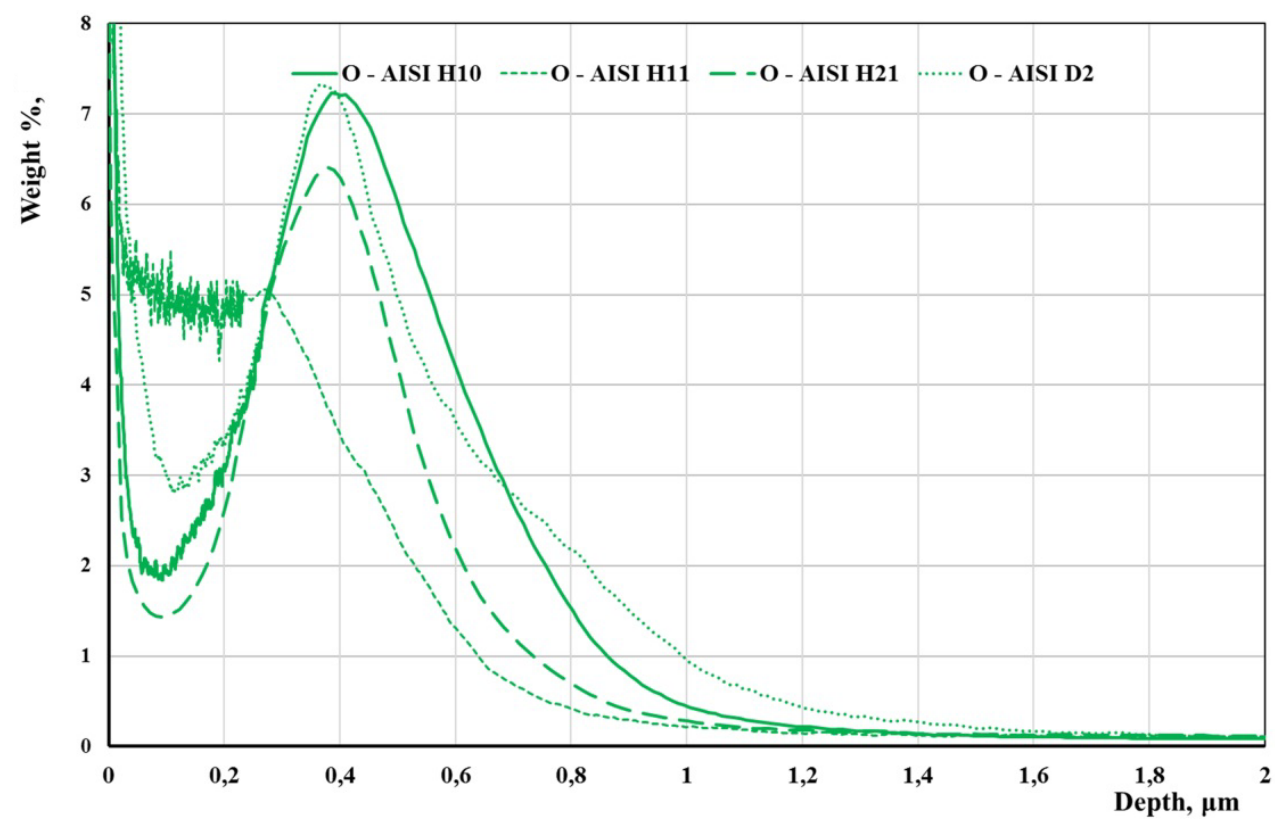

Fig. 11.GDOES concentration-depth profiles of oxygen of the ONC samples.

\section{Discussions}

At low pressure conditions (stage I), where unstable compound layer nuclei are formed, a large period of time is needed to establish local equilibrium of gas phase atmosphere with the solid substrate. This effect is highlighted during vacuum ONC of the tool steels because much more nitrogen is taken by the alloying elements before attaining saturation at the surface since the alloy nitride phases develops in direct contact with the gas atmosphere. The stronger nitride forming elements are supposed to combine first with nitrogen until they are exhausted [21]. However, although thermodynamically possible, a certain solid state reaction, where the number of variables is high, may not be kinetically favorable. As the nitrogen concentration in the diffusion layer grows, the driving force for precipitation of the alloying elements nitrides certainly increases. In that event, since the $\mathrm{Cr}$ diffuses more rapidly in ferrite than the other metallic alloying elements (such as $\mathrm{V}, \mathrm{Mo}, \mathrm{W}$ ), $\mathrm{Cr}$ containing nitride precipitates are encountered even in the ONC H21 - the tool steels with lower $\mathrm{Cr}$ content. The $\mathrm{Cr}$ in this area participates in the formation of $\mathrm{Cr}_{2} \mathrm{~N}$ phase where the ordered arrangement of metal atoms corresponds to hcp lattice and the nitrogen atoms are distributed in the interstitial voids such as in $\varepsilon-\mathrm{Fe}_{2-3}(\mathrm{~N}, \mathrm{C})$. Simultaneously, the precipitation of the nitrides of the alloying elements has no considerable effect on the concentration distribution in depth of the diffusion layer of all samples, although the coarsening process is additionally benefited from the preliminary single tempering and, therefore, the lower amount of nitride forming elements tied as carbides.

The discontinuous coarsening of fine nitrides involves also the growth of the cubic martensite from the different nucleation sides. The quantitative information for the full phase composition drown by the XRD results could be misleading to a certain extend because the lattice structure of many nitrides is similar to that of the carbides.

The increase in pressure value (stage II) increases the thermodynamic stability of the iron nitrides together with the surface nitrogen concentration that leads to the occurrence of iron nitrides at the surface. The results obtained from the surface composition and phase 
analysis of the compound layer demonstrate that the reaction product after 7 hours of ONC is composed of pure $\varepsilon$ - iron carbonitride. As opposed to alloying niritrides, only the diffraction line of the $\varepsilon-\mathrm{Fe}_{2-3}(\mathrm{~N}, \mathrm{C})$ is considered to be unaffected by the superimpositions. Concerning the lack of $\gamma^{\prime}$ - nitride, this phase appears to be absent during the ONC of the tool steels because of four main reasons: 1) crystallographic resemblance of $\varepsilon, \mathrm{Cr}_{2} \mathrm{~N}$, orthorhombic carbides; 2) the higher carbon content in the surface area (coming from $\mathrm{C}$, released from the alloy carbides transformation[22] together with that from the external source) that stabilizes the $\varepsilon$-phase [23]; 3) the low solubility range of $\mathrm{N}$ and $\mathrm{C}$ in $\gamma^{\prime}-\mathrm{Fe}_{4} \mathrm{~N}$ [24]; 4) the delayed compound layer formation because M. Somers at al. [25] proposed that in contrast to the treatment of iron, the $\gamma$ '-formation during nitrocarburizing needs prolong process time. From the results of the present study is clear that the thickness of the compound layer within the vacuum ONC depends on the pressure, composition and phase structure of the underlying carbonitride film.

Based on the thermodynamic calculation it is seen that the $\varepsilon$-phase is becoming stable with increasing of nitrogen and a very small increase of carbon. From the diagram is clearly seen that no single $\gamma^{\prime}$-phase regions could be formed during the vacuum ONC process compared to the pure iron. The computational results show the large phase stability of coexisting $\varepsilon$, cementite and ferrite phases and their stability increase with the nitrogen and carbon concentration even at very low nitrogen concentrations. The microstructure and XRD results are consistent with these FactSage predictions. The increase of carbon stabilizes the $\varepsilon$-phase that is in a good agreement with the isopleths plot. However the mole fractions of these phases depends on both $\mathrm{N}$ and $\mathrm{C}$ content in the steel substrate that may lead to difficulties in their experimental detection. Since the stage II involves higher pressure in the chamber, the final phase stabilities should be determined by this stage. The oxygen bearing atmosphere allows the oxygen to dissolve into the $\varepsilon$-iron carbonitride but at $570{ }^{\circ} \mathrm{C}$ oxides are not likely to be formed due to the presence of highly active hydrogen in the atmosphere. When the oxygen activity increases (during the cooling stage [15]) the magnetite grows in the pore structure of the surface carbonitride layer. The discrepancy between the experimental and predicted phase composition may be due to neglecting the occurrence of oxides when lowering the temperature.

The $\varepsilon$-carbonitride with relatively low nitrogen content (as in the ONC H11 steel) may tend to decompose into $\varepsilon$-phase with higher nitrogen content at the surface and carbides and/or oxides at the innermost area of the layer. Close to the compound/diffusion layer interface judging from the composition some intermediate $\varepsilon$-carbonitride-magnetite phases are likely to be formed. Depending on the concentration of the interstitially dissolved in $\varepsilon$ elements, the excess nitrogen from the carbonitride-oxide transformation could either dissolves in the $\varepsilon-\mathrm{Fe}_{2-3}(\mathrm{~N}, \mathrm{C})$ without causing local nitrogen enrichment but displaying a steeper nitrogen concentration gradient (as in AISI H10, H11 and D2 steels) or participate in nitrogen recombination (as in AISI H21 steel). This results are in agreement with earlier observations showing that microvoids are observed because of the iron vacancies formed during oxidation [26], but more experimental work is needed to verify this interpretation.

\section{Conclusions}

The present study demonstrates a new solution for successful surface modification of tool steels and its efficacy. According to the results it could be claimed that during the first stage of the vacuum $\mathrm{ONC}$ local equilibrium condition is likely to prevail at phase interface in the diffusion layers that appeared to be time, pressure and substrate composition dependent. Concerning the overall alloy elements content, it could be concluded that the higher concentration of the nitride forming elements increases the driving force for the coarsening reaction. The coarsening process is additionally enhanced by the preliminary single 
tempering and, therefore, the lower amount of nitride forming elements tied as carbides. The increase in pressure value that increases the thermodynamic stability of the iron nitrides results in the formation of thin $\varepsilon$ - iron carbonitride compound layer. The thickness of the compound layer during ONC depends on not only on the volume fraction of the nitride forming elements but on their type and interphase distribution. Close to the compound/diffusion layer interface an intermediate $\varepsilon$-carbonitride-oxide phase region is likely to be formed that turn to magnetite containing compound layer during cooling.

A customized diagram is successfully developed by computational thermodynamics for the vacuum ONC of tool steels. This diagram predicts a large area of coexisting $\varepsilon$, cementite and ferrite phases under the low pressure conditions of the process. It is seen that the model satisfactorily describes the experimental data to the detected nitrogen and carbon contents. The discrepancy between the experimental and predicted phase composition is due to neglecting the occurrence of iron oxides. The isotherms do not describe equilibrium gas mixture composition and substrate composition but when incorporating the thermodynamic predictions with the kinetic simulations, the ONC process of different alloys could be optimized.

The paper reflects the outcomes of the project № 16 - FMME - 02, financed by the Fund "Scientific Research"of the University of Ruse "A. Kanchev". The authors would like to thank D-r Slavcho Topalski for his help with the execution of GDOES analysis in Fraunhofer Institute (für Werkstoff- und Strahltechnik IWS).

\section{References}

1. M. Nikolova, P. Danev, I. Dermendzhiev, J Mat Sci Tech (Bulgaria), 21 2, 84-96 (2013)

2. K. Shetty, S. Kumar, P. R. Rao, Surf Coat Tech 20310, 1530-1536 (2009)

3. J. Wang, J. Xiong, Q. Peng, H. Fan, Y. Wang, G. Li, B. Shen,Mater Charact 60,197 203 (2009)

4. M. Teimouri, M. Ahmadi, N. Pirayesh, M. Khoee, H. Khorsand, S. Mirzamohammadi, JAlloys Compd, 477 1-2, 591-595 (2009)

5. M. HeydarzadehSohi, M. Ebrahimi, A. HonarbakhshRaouf, F. Mahboubi, Surf Coat Tech 205, 84-89(2010)

6. M. Tercelj, A. Smolej, P. Fajfar, R. Turk, Tribol Intl 40, 374-384(2007)

7. P. C. King, R. W. Reynoldson, A. Brownrigg, J. M. Long, Surf Eng21 2, 86-98 (2005)

8. T. Bell, Heat Treat. Met., 2 2,39-49 (1975)

9. S.-H. Chang, K.-Ts. Huang, Y.-Hs. Wang, Mater Trans, 53 4, 745 - 751 (2012)

10. A. Khadar Syed, J. Hardell, B.Prakash, Estonian J. of Eng 16 2, 123-134 (2010)

11. K. H. Lee, K. S. Nam, P. W. Shin, D.Y. Lee, Yo-S. Song, Mater Lett.57, 2060 - 2065 (2003)

12. G.H. Farrahi, H. Ghadbeigi, JMater. Process. Technol.174, 318-324 (2006)

13. F. Ashrafizadeh, Surf Coat Tech174-175, 1196-1200 (2003)

14. M. Rosso, A. Bennani, Trans on Eng Sci17,25-134 (1997)

15. D. Nikolov, M. Nikolova, Scientific Technical J Mater Sci. Non-equilibrium phase transformations 3, 29-33, (2015)

16. E.J. Mittemeijer, ASM Handbook, Vol. 4A, Steel Heat Treating Fundamentals and Processes, J. Dossett and G.E. Totten (editors), 619-646 (2013)

17. P. Danev, Proc. of Scientific Session, $R U \& S U^{\prime 2004, ~ E n g . ~ S c i . ~(i n ~ B u l g a r i a n) ~} 41$ 2, $73-$ 77 (2004)

18. C.W. Bale, E. Bélisle, P. Chartrand, S.A. Decterov, G. Eriksson, A.E. Gheribi, K. Hack, I.-H. Jung, Y.-B. Kang, J. Melançon, A.D. Pelton, S. Petersen, C. Robelin, J. Sangster, 
P. Spencer, M-A. Van Ende, FactSage thermochemical software and databases, 20102016 Calphad, 54, 35-53 (2016)

19. O. Salas, J. Oseguera, N. Garci, U. Figueroe, J.Mat Eng \&Perf, 10 6, 649-655 (2001)

20. S. S. Hosmani, Metal Mater.Eng.19 1, 65-84 (2013)

21. S.M. Hassani-Gangaraj, M.Guagliano, Appl. Surf.Sci271, 56-163(2013)

22. P.C King, R. W. Reynoldson, A. Brownrigg, J. M. Long, Surf Eng 212, 86-96 (2005)

23. Mei Yang, Dissertation, Worcester Polytechnic Institute, 1-139 (2012)

24. M.A.J. Somers, International Heat Treatment and Surface Engineering IFHTSE Global 21, 51, 7-16 (2011)

25. M.A.J. Somers, E.J. Mittemeijer, Heat Treating, Proc. 17th ASM Heat Treating Society Conference, ASM International, 321-330 (1998)

26. R. H. Jutte, B.J. Kooi, M. A. J. Somers, E.J. Mittemeijer, Oxid. Met 48 1/2, 87-109 (1997). 